\title{
Como se relacionam as crianças em contexto de jogo? um estudo realizado em crianças do $1^{0}$ cicllo
}

\author{
How do children relate in game context? a study of primary school children
}

\section{¿Cómo se relacionan los niños en el contexto del juego? un estudio con alumnado de primer ciclo}

\author{
Inês Peixoto Silva* \\ Ana Isabel Silva \\ Beatriz Oliveira Pereira ${ }^{* * *}$
}

Resumo

O jogo é um comportamento característico de qualquer criança constituindo-se como promotor do seu desenvolvimento pois através da sua prática estas interagem entre si em brincadeiras aprendendo a negociar, cooperar e trabalhar em equipa. Objetivo: Compreender como se relacionam as crianças em contexto de jogo. Metodologia: participaram 35 alunos (19 meninos e 16 meninas), 18 do $1^{\circ}$ ano e 17 do $3^{\circ}$ ano com idades entre os 6 e 9 anos $(7,2 \pm 1,1)$. Foi utilizado um guião de observação construído para o efeito com 3 subcategorias para a categoria "relações interpessoais": 1) Ser capaz de trabalhar em equipa; 2) Ser sociável, relaciona-se facilmente com o próximo; 3) Ter em consideração as ideias e objetivos dos elementos do grupo. Foi realizado um jogo entre duas equipas com objetivo de percorrer um de três percursos pontuados de acordo com o grau de dificuldade. Resultados: nas 3 subcategorias verificou-se que a maioria dos alunos, independentemente do género e ano de escolaridade apresentou este comportamento de forma positiva não se verificando diferenças estatisticamente significativas $(p<0,05)$. Conclusões: as crianças, na sua maioria, demonstraram relacionar-se com os pares no decorrer do jogo sendo assim essencial promover na criança estas competências essenciais ao seu desenvolvimento emocional e social.

Palavras-chave: Jogo. Relações Interpessoais. Criança.

Recebido em 21/10/2019 - Aprovado em 09/04/2020

http://dx.doi.org/10.5335/rep.v27i2.11430

Doutora em estudos da Criança, Universidade do Minho. Professora convidada da Universidade do Minho, Portugal e membro do Centro de Investigação em Estudos da Criança. Orcid: https://orcid.org/0000-0003-4547-5336. E-mail: inexota@hotmail.com.

** Doutora em estudos da criança e membro do Centro de Investigação em Estudos da Criança, Universidade do Minho, Portugal. Orcid: https://orcid.org/0000-0002-5751-3902.E-mail: anasilva0883@gmail.com

*** Doutora em estudos da criança, professora catedrática da Universidade do Minho e membro do Centro de Investigação em Estudos da Criança, Instituto de Educação, Universidade do Minho, Portugal. Orcid: https://orcid.org/00000003-4771-9402. E-mail: beatriz@ie.uminho.pt 


\section{Abstract}

Play is a typical behaviour of any child and a promoter of their development, through which they interact, along the play, and learn to negotiate, cooperate and work in teams. Objective: Understand how children relate in a context of game. Methodology: 35 students (19 boys and 16 girls), 18 from the 1 st year and 17 from the $3 \mathrm{rd}$ year aged between 6 and 9 years $(7.2 \pm 1.1)$ participated. A purpose-built observation guide was used with 3 subcategories for the category "interpersonal relationships": 1) Being able to work in a team; 2) Be sociable, easily relate to others; 3 ) Consider the ideas and goals of the group members. A game was held between two teams with the objective of covering one of three courses scored according to the degree of difficulty. Results: In the 3 subcategories it was verified that the majority of students, despite the gender and grade, showed this positive behaviour, without a statistically significant difference $(p<0.05)$. Conclusions: Most children have shown to relate to peers throughout the game, and it is essential to promote in children these skills, essential for their emotional and social development.

Keywords: Play. Interpersonal relationships. Children.

\section{Resumen}

El juego es un comportamiento característico de los niños y es un importante promotor de su desarrollo integral, a través de la práctica ellas interactúan, negocian, cooperan y trabajan en equipo. Objetivo: Comprender se relacionan los niños en el contexto del juego. Metodología: participaron 35 estudiantes (19 niños y 16 niñas), 18 del primer año y 17 del tercer año, con edades entre 6 y 9 años (7.2 \pm 1.1 ). Se utilizó una guía de observación especialmente diseñada con 3 subcategorías para la categoría "relaciones interpersonales": 1) Poder trabajar en equipo; 2) Ser sociable, relacionarse fácilmente con los demás; 3) Considerar las ideas y objetivos de los miembros del grupo. Se realizó un juego entre dos equipos con el objetivo de cubrir uno de los tres campos anotados de acuerdo con el grado de dificultad de la tarea. Resultados: en las 3 subcategorías verificadas, la mayoría de los estudiantes mostraron un comportamiento positivo, sin verificar las diferencias estadísticamente utilizadas ( $p$ <0.05). Conclusiones: se ha demostrado que la mayoría de los niños se relacionan con sus compañeros en el desarrollo de los juegos, siendo necesario promover esas habilidades con el fin de contribuir a su desarrollo físico, psíquico, social y emocional.

Palabras clave: Juego. Relaciones interpersonales. Niños.

\section{Introdução}

O jogo é uma atividade comum a qualquer criança, permite que esta entre num mundo imaginário, assuma personagens, recrie situações através das quais exprime os seus sentimentos aprendendo a adaptar-se às exigências que o mundo lhe confere no momento. É o modo de aprender e descobrir o mundo, uma forma de movimento, comunicação, exploração e aprendizagem, um meio essencial à socialização sendo a sua principal característica a longevidade individual e social (MIHAELA, 2013).

A mesma autora acredita na existência de uma relação próxima entre jogo e desenvolvimento, onde o jogo é promotor não só da componente motora mas também da cognitiva, emocional e social. Sob ponto de vista motor, o jogo permite o desenvolvimento da destreza e força física (GINSBURG, 2007) e ainda a diminui- 
ção dos efeitos negativos dos estilos de vida sedentários, cada vez mais patentes na infância (PELLEGRINI \& BOHN, 2005), promovendo ainda competências cognitivas como a linguagem expressiva, o sentido numérico, o raciocínio e a resolução de problemas (HURWITZ, 2002), a criatividade, a imaginação (MIHAELA, 2013; MILTEER \& GINSBURG, 2012; GINSBURG, 2007; HURWITZ, 2002) a capacidade de assumir riscos e de lidar com os seus medos, capacidade de resiliência e superação de desafios (MILTEER \& GINSBURG, 2012) a criação de algo novo, a descoberta e pensamento (HURWITZ, 2002). Todavia, para além das competências acima referidas, o jogo como momento privilegiado de interação social (HUIZINGA, 2003; KISHIMOTO, 1998) possibilita também a promoção da capacidade de negociação (MILTEER \& GINSBURG, 2012), o trabalho de equipa, a cooperação entre pares (MILTEER \& GINSBURG, 2012; HURWITZ, 2002; NETO, 1997), o diálogo, o respeito pelo outro e pelas regras (FILGUEIRAS, 2002) ou seja as relações interpessoais e ainda a melhoria da perceção corporal, autoeficácia, autoestima e bem-estar psicológico (NETO, 1997).

As relações interpessoais são essenciais no processo de formação das crianças, essencialmente sob o ponto de vista do seu desenvolvimento social e emocional, estas interagem entre si em brincadeiras e jogos, aprendendo a negociar, a cooperar e a trabalhar em equipa para atingirem um objetivo (MENDES, 2012). Segundo Brougère (1998, p. 112) só existe jogo quando "a criança dispõe de significações, de esquemas em estruturas que ela constrói no contexto de interações sociais que lhe dão acesso a eles."

Estas competências, que permitem o relacionamento entre pares, podem ser essenciais a longo prazo, num contexto pessoal e profissional na medida em que é também considerada uma das mais relevantes características de um empreendedor. O jogo e a brincadeira devem assim ser valorizados no contexto escolar, como meio facilitador de aprendizagens primordiais ao seu processo de formação.

Apesar de todos os benefícios evidentes associados à prática do jogo, a sua aplicação tem sido, ao longo dos anos, negligenciada. Analisada a literatura sobre esta temática, em particular sobre as caraterísticas empreendedoras em crianças, verificamos que existe uma grande lacuna científica, uma vez que estes estudos têm sido realizados com adultos e em contexto laboral. No nosso entendimento é necessário ir à escola, às crianças no início da escolaridade uma vez que estas se encontram numa fase de desenvolvimento e de aprendizagens de excelência. Este estímulo, desde cedo, permitiria também responder a um mundo em constante mudança que necessita de novas respostas para novos problemas. 
São já alguns os programas a ser implementados em escolas com vista a desenvolver as caraterísticas empreendedoras, mas escasseiam os trabalhos científicos que avaliem esses programas.

Compreendemos quão arriscado seria enveredar por este caminho, mas a nossa motivação para aprofundar estas questões não deixou que as dificuldades se sobrepusessem à necessidade de conhecer esta realidade que se demonstrou desafiante.

\section{Objetivos}

Compreender como se manifesta a característica "Relações interpessoais" em contexto de jogo em crianças do $1^{0}$ ciclo.

\section{Metodologia}

Delineamento da investigação: trata-se de um estudo exploratório com recurso a metodologias mistas. Este estudo pretendeu dar voz às crianças utilizando instrumentos não convencionais por sabermos que os estudos realizados com crianças necessitam de ser aprofundados e, por isso, o recurso ao jogo e discussão livre entre as crianças para a resolução de um problema, foi essencial para a recolha dos dados.

Participantes: 37 alunos sendo 18 alunos do $1^{\circ}$ ano de escolaridade (9 do género feminino e 9 do género masculino) e 19 alunos do $3^{\circ}$ ano ( 9 do género feminino e 10 do género masculino). As 37 crianças tinham idades compreendidas entre os 6 e os 9 anos $(7,2 \pm 1,1)$. O estudo foi realizado numa escola do $1^{\circ}$ ciclo do ensino básico da área urbana de Braga.

Instrumentos: Foi desenvolvido um jogo para testar as competências empreendedoras das crianças, sendo uma delas as "relações interpessoais". O diálogo entre os vários elementos de ambas as equipa foi gravado e transcrito para análise do seu conteúdo. 
Protocolo do jogo:

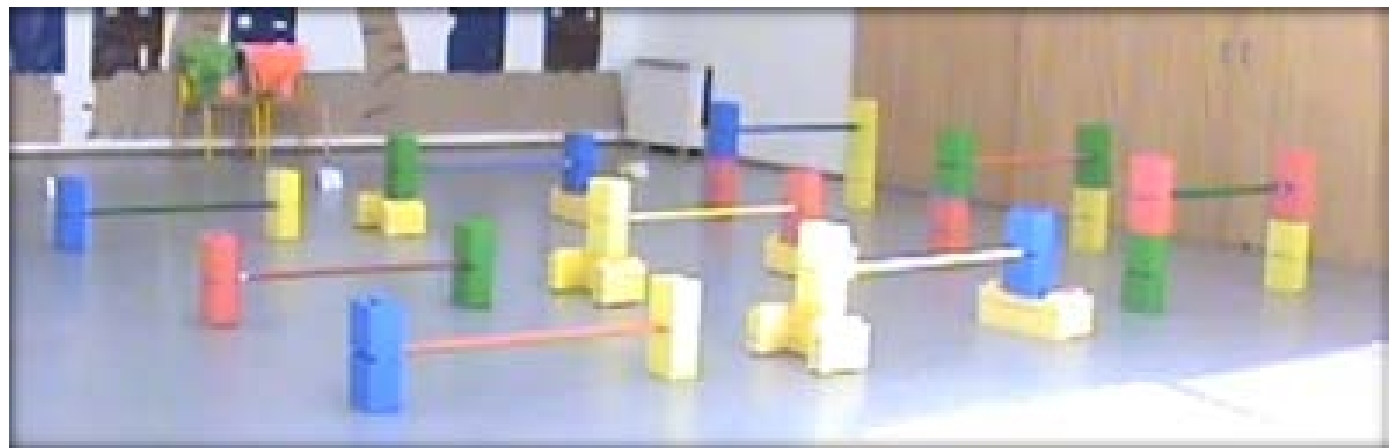

Fonte: autora.

Idades: $1^{\circ}$ e $2^{\circ}$ ciclo

Participantes: podem participar duas ou mais equipas mistas, de quatro elementos. O número de equipas varia em função do número de participantes disponíveis para a realização do jogo.

Objetivo para as crianças: transpor um percurso com sucesso com três variantes de transposição com o intuito de obter a máxima pontuação para a equipa no final de todas as variantes.

Objetivo para a investigação: identificar características empreendedoras em contexto de jogo estruturado. As características avaliadas são assunção do risco, autoconfiança, criatividade/inovação, identificação de oportunidades, liderança/ tomada de decisão, organização/planeamento, persistência/resistência ao fracasso e relações interpessoais.

Descrição: o jogo consiste na escolha de um de três percursos existentes. A escolha deve ser ponderada na medida em que os percursos são pontuados de acordo com o grau dificuldade. Em cada um dos percursos são dispostas três barreiras espaçadas entre si cuja altura vai aumentando progressivamente sendo o percurso 1 de menor dificuldade e o 3 de maior dificuldade. 
No final de cada percurso encontra-se uma caixa com diferentes pontuações, ou seja, no percurso 1 a caixa contém papeis de 1 ou 2 pontos, no percurso 2,2 ou 3 pontos e no percurso 3,3 ou 4 pontos.

Na primeira variante, o objetivo é que as crianças ultrapassem as barreiras transpondo-as por cima, na segunda variante por baixo e na terceira intercalando por cima e por baixo. Deve ter-se em atenção que, na segunda variante, deve inverter-se a ordem das pontuações de modo a que o percurso 1 se mantenha como o de menor e o 3 de maior dificuldade.

Cada equipa terá até 3 minutos para decidir qual a ordem de partida de cada um dos seus elementos que poderá alterar-se entre variantes.

Uma equipa de cada vez e, individualmente, cada aluno opta por um dos percursos, retira o papel correspondente, abre-o, lê em voz alta e coloca-o numa outra caixa atribuída à sua equipa que se encontra no fundo da sala. Em seguida deve correr o mais rapidamente possível pela lateral destinada para o efeito e toca na mão do colega que parte de imediato e assim sucessivamente durante três minutos. No final dos 3 minutos o jogo termina, estes sentam-se e recomeça para a equipa adversária. Após ambas as equipas terminarem o jogo, estas reúnem-se para a contagem dos pontos conseguidos. A contagem é realizada pelo mediador em voz alta e mostrando sempre os pontos a todos os elementos. A soma dos pontos é realizada oralmente por todos os participantes. No final da contagem são escritas as pontuações conseguidas por cada equipa. Aquando do término da atividade somam-se todas as pontuações verificando aí qual a equipa vencedora.

Duração: três minutos para cada equipa. Visto ser um jogo em que, para cada variante, os alunos têm de optar por um de três percursos com diferentes níveis de dificuldade é importante que a sua duração seja por tempo e não por número de percursos pois é essencial que a criança aja em função do risco / benefício da sua opção caso contrário, terá tempo para ultrapassar o percurso com maior dificuldade na perfeição sem que a sua ação tenha uma consequência.

Disposição do material: em todos os percursos as barreiras têm o comprimento de 121 centímetros $(\mathrm{cm})$ e as três barreiras são espaçadas por $110 \mathrm{~cm}$. No percurso 1 as barreiras estão colocadas a uma altura do solo de $15,5 \mathrm{~cm}$ e por isso, é designado como nível mais fácil. No percurso 2 , as barreiras estão colocadas a uma altura do solo de 31,5 cm e por isso é denominado como nível médio e no percurso 3 as 
barreiras estão colocadas a uma altura do solo de $46,5 \mathrm{~cm}$ e por isso é denominado como o nível mais difícil.

Nos níveis de maior dificuldade deve considerar-se, na primeira variante, a estrutura física dos alunos e caso se verifique que para parte considerável não é possível a sua transposição então deve ser ajustada a altura do solo da barreira. Na segunda variante, a barreira não deve ultrapassar a altura da cintura da maioria das crianças.

Material: 24 Blocos, respetivas barreiras (9), várias bases de suporte com $4 \mathrm{~cm}$ para aumentar a altura das barreiras, 5 caixas ( 3 são para os percursos e 2 para a colocação das pontuações de cada equipa). Podem ser utilizados diferentes materiais desde que as barreiras tombem se tocadas pelas crianças e com isso as condições de segurança asseguradas.

Procedimentos: inicialmente foram pedidas todas as autorizações necessárias para concretização do estudo nomeadamente ao Conselho Científico do Instituto de Educação da Universidade do Minho, à Direção Geral de Inovação e Desenvolvimento Curricular, à Comissão Nacional de Proteção de Dados (autorização $\mathrm{n}^{0}$ 842/2016) à Comissão de ética para as Ciências Sociais e Humanas da Universidade do Minho, ao agrupamento de escolas, aos professores, encarregados de educação e crianças que deram o seu consentimento informado tendo sido informadas que a sua participação era voluntária e poderiam desistir a qualquer momento se o entendessem.

Para a análise dos dados recolhidos foram construídas à priori as subcategorias referentes à categoria relações interpessoais, tendo por base a revisão da literatura.

Quadro 1 - Categoria e subcategorias

\begin{tabular}{|c|l|}
\hline Categoria & \multicolumn{1}{|c|}{ Subcategoria } \\
\hline \multirow{4}{*}{ Relações Interpessoais } & Ser capaz de trabalhar em equipa \\
\cline { 2 - 2 } & Ser sociável, relaciona-se facilmente com o próximo \\
\cline { 2 - 2 } & Ter em consideração as ideias e objetivos dos elementos do grupo \\
\hline
\end{tabular}




\section{Tratamento dos dados:}

Foram utilizadas análises descritivas para quantificar os comportamentos observados, o teste Kruskal-Wallis para verificar as diferenças entre as subcategorias quanto ao género e idade e análises interpretativas em cada uma das subcategorias para a "relações interpessoais". Cada aluno foi analisado com base na observação das gravações realizadas.

\section{Resultados}

A observação do jogo permitiu observar três tipos de comportamento: Comportamento positivo (CP) - verifica-se o comportamento; Comportamento Inverso (CI) - Verifica-se o comportamento, contudo é demonstrado de modo inverso e Comportamento não observado (CNO) - não se verifica o comportamento.

No quadro 2 consta o número de comportamentos positivos (CP), inversos (CI) e não observados (CNO) em cada uma das subcategorias da categoria "relações interpessoais" em função do género.

Quadro 2 - Relações interpessoais das crianças por género

\begin{tabular}{|c|c|c|c|c|c|c|c|c|c|c|}
\hline & \multicolumn{3}{|c|}{$\begin{array}{c}\text { MENINOS }(n=19) \\
n(\%)\end{array}$} & \multicolumn{3}{|c|}{$\begin{array}{c}\text { MENINAS }(n=16) \\
n(\%)\end{array}$} & \multicolumn{3}{|c|}{$\begin{array}{c}\text { TOTAL }(n=35) \\
n(\%)\end{array}$} \\
\hline & & $\mathrm{CP}$ & $\mathrm{Cl}$ & $\mathrm{CNO}$ & $\mathrm{CP}$ & $\mathrm{Cl}$ & CNO & $\mathrm{CP}$ & $\mathrm{Cl}$ & CNO \\
\hline \multirow{3}{*}{$\begin{array}{l}\text { Relações } \\
\text { Interpessoais }\end{array}$} & 1 & $15(78,9)$ & $4(21,1)$ & $0(0,0)$ & $13(81,3)$ & $3(18,8)$ & $0(0,0)$ & $28(80,0)$ & $7(20,0)$ & $0(0,0)$ \\
\hline & 2 & $11(57,9)$ & $8(42,1)$ & $0(0,0)$ & $14(87,5)$ & $2(12,5)$ & $0(0,0)$ & $25(71,4)$ & $10(28,6)$ & $0(0,0)$ \\
\hline & 3 & $15(78,9)$ & $3(15,8)$ & $1(5,3)$ & $11(68,8)$ & $4(25,0)$ & $1(6,3)$ & $26(74,3)$ & $7(20,0)$ & $2(5,7)$ \\
\hline \multicolumn{2}{|l|}{ Total } & $41(71,9)$ & $15(26,3)$ & $1(1,8)$ & $38(79,2)$ & $9(18,8)$ & $1(2,1)$ & $79(75,2)$ & $24(22,9)$ & $2(1,9)$ \\
\hline
\end{tabular}

Legenda: CP - Comportamentos positivos; Cl- comportamentos inversos; CNO - comportamentos não observados

No quadro 3 consta o número de comportamentos positivos (CP), inversos (CI) e não observados (CNO) em cada uma das subcategorias da categoria "relações interpessoais" em função do ano de escolaridade. 
Quadro 3 - Relações interpessoais das crianças por ano de escolaridade

\begin{tabular}{|c|c|c|c|c|c|c|c|c|c|c|}
\hline & & \multicolumn{3}{|c|}{$\begin{array}{c}1{ }^{\circ} \mathrm{ANO}(\mathrm{N}=18) \\
\mathrm{N}(\%)\end{array}$} & \multicolumn{3}{|c|}{$\begin{array}{c}\text { 3o ANO }(\mathrm{N}=17) \\
\mathrm{N}(\%)\end{array}$} & \multicolumn{3}{|c|}{$\begin{array}{c}\text { TOTAL (N=35) } \\
\mathrm{N}(\%)\end{array}$} \\
\hline & & $\mathrm{CP}$ & $\mathrm{Cl}$ & CNO & $\mathrm{CP}$ & $\mathrm{Cl}$ & CNO & $\mathrm{CP}$ & $\mathrm{Cl}$ & CNO \\
\hline \multirow{3}{*}{$\begin{array}{l}\text { Relações } \\
\text { Interpessoais }\end{array}$} & 1 & $13(72,2)$ & $5(27,8)$ & $0(0,0)$ & $15(88,2)$ & $2(11,8)$ & $0(0,0)$ & $28(80,0)$ & $7(20,0)$ & $0(0,0)$ \\
\hline & 2 & $14(77,8)$ & $4(22,2)$ & $0(0,0)$ & $11(64,7)$ & $6(35,3)$ & $0(0,0)$ & $25(71,4)$ & $10(28,6)$ & $0(0,0)$ \\
\hline & 3 & $11(61,1)$ & $6(33,3)$ & $1(5,6)$ & $15(88,2)$ & $1(5,9)$ & $1(5,9)$ & $26(74,3)$ & $7(20,0)$ & $2(5,7)$ \\
\hline \multicolumn{2}{|l|}{ Total } & $38(70,4)$ & $15(27,8)$ & $1(1,9)$ & $41(80,4)$ & $9(17,6)$ & $1(2,0)$ & $79(75,2)$ & $24(22,9)$ & $2(1,9)$ \\
\hline
\end{tabular}

Legenda: CP - Comportamentos positivos; $\mathrm{Cl}$ - comportamentos inversos; CNO - comportamentos não observados

Relativamente a esta característica, Relações Interpessoais, mais concretamente à subcategoria 1 "É capaz de trabalhar em equipa" aferimos que, este comportamento foi verificado na totalidade dos alunos no decorrer do jogo, no entanto, uns de forma positiva e outros, inversa. Assim, o CP foi observado em diferentes situações tais como, ter em consideração as opiniões do grupo antes de tomar uma decisão; negociar com os colegas, sem impor a sua vontade e auxiliar os colegas de equipa com intuito do sucesso coletivo. Por sua vez, aqueles em que se verificaram CI não demonstraram interesse pelas opiniões ou vontades dos colegas de equipa nem não pensam ou agem coletivamente.

A análise relativa ao género não demonstrou diferenças estatisticamente significativas $(\mathrm{p}>0,05)$. Na maioria dos alunos, de ambos os géneros, verificaram-se CP (78,9\% e $81,3 \%$ respetivamente). Relativamente aos CI, também os resultados entre meninos e meninas foram semelhantes ( $21,1 \%$ e $18,8 \%$ respetivamente).

Quanto à idade também não se verificaram diferenças estatisticamente significativas ( $>00,05)$. Constatou-se que, a maioria dos alunos, de ambas as faixas etárias, revelou $\mathrm{CP}(72,2 \%$ para a faixa etária mais baixa e $88,2 \%$ para a faixa etária mais alta) e $27,8 \%$ dos alunos mais novos e $11,8 \%$ dos mais velhos manifestaram CI. Assim, os alunos mais velhos destacaram-se ligeiramente ao evidenciarem uma maior percentagem de CP.

Também na subcategoria 2 "É sociável, relaciona-se facilmente com o próximo", constatou-se que, a totalidade dos alunos revelou este comportamento no decorrer do jogo, no entanto, uns de forma positiva e outros, inversa. Assim, o CP foi observado através da interação entre a própria equipa, mas também com a adversária. Por sua vez, os CI verificaram-se pela ausência de interação com os colegas, isolando-se das brincadeiras e da própria ação do jogo. 
No que respeita ao género, apesar de não se constatarem diferenças estatisticamente significativas ( $>0,05$ ), verificou-se um destaque do género feminino $(87,5 \%)$ relativamente ao masculino $(57,9 \%)$ na observação de CP. Já nos CI o destaque recai sobre o género masculino onde se observaram $42,1 \%$, percentagem consideravelmente superior à observada no género feminino (12,5\%).

Quanto à idade, os resultados assemelham-se, não se verificando também diferenças estatisticamente significativas $(p>0,05)$ havendo, contudo, na observação de CP, um ligeiro destaque para os alunos mais novos $(77,8 \%)$ comparativamente com os mais velhos $(64,7 \%)$. O mesmo se verifica nos CI com o ligeiro destaque agora, para a faixa etária mais alta $(35,3 \%)$ comparativamente com a mais baixa $(22,2 \%)$.

No que concerne à subcategoria 3 "Tem em consideração as ideias e objetivos dos elementos do grupo", e tal como verificado nas categorias anteriores, este comportamento observou-se no decorrer do jogo, no entanto, uns de forma positiva e outros, inversa. Assim, o CP foi observado através da consideração demonstrada pelas opiniões e vontades dos colegas e os CI observaram-se através da imposição da sua vontade, sem considerar a dos colegas. Os CNO pertencem a alunos em que, no decorrer de todo o jogo se alhearam de qualquer posição relativamente a opiniões ou decisões dos colegas e também não tomaram iniciativa de demonstrar qual a sua vontade ou opinião. Nesse sentido não foi possível verificar este comportamento.

Analisando por género, não se constataram diferenças estatisticamente significativas $(\mathrm{p}>0,05)$ todavia os $\mathrm{CP}$ corresponderam à maior percentagem de comportamentos observados tanto nos alunos do género masculino como do feminino (78,9\% e 68,8\% respetivamente) destacando-se, contudo, nos meninos, uma percentagem mais elevada. Relativamente aos CI, os resultados entre géneros também se assemelham com $15,8 \%$ dos meninos e $25,0 \%$ das meninas a manifestarem este comportamento constatando-se assim um ligeiro destaque para as meninas.

No que respeita à idade, tal como se verificou anteriormente, não se constataram diferenças estatisticamente significativas $(p>0,05)$ contudo a maioria dos alunos apresentou, em ambas as faixas etárias, $\mathrm{CP}(61,1 \%$ nos alunos mais novos e 88,2\% nos mais velhos), destacando-se assim, os alunos mais velhos. Quanto aos CI constataram-se em $33,3 \%$ dos alunos mais novos e 5,9\% dos mais velhos deste modo, os alunos mais novos relevaram mais este tipo de comportamento do que os mais velhos. 
Somadas todas as subcategorias, constatamos que independentemente do género e idade na maioria dos alunos $(75,2 \%)$ se verificaram CP, 22,9\% dos alunos manifestaram CI e apenas em 1,9\% dos alunos não se observou o comportamento.

Analisando por género e idade os comportamentos são bastante semelhantes. A grande percentagem registada nos alunos refere-se a $\mathrm{CP}$ (71,9\% nos meninos e $79,2 \%$ nas meninas e $70,4 \%$ na faixa etária mais baixa e $80,4 \%$ para a mais alta). Quanto aos CI verificaram-se em $26,3 \%$ dos meninos e 18,8\% das meninas e $27,8 \%$ dos alunos mais novos e 17,6\% dos mais velhos. Relativamente aos CNO, apenas se verificou um caso em ambos os géneros e idades. Assim, tanto nos totais como nos valores de cada subcategoria foi nos $\mathrm{CP}$ que os alunos apresentaram percentagens mais elevadas, independentemente do género e idade.

\section{Discussão dos Resultados}

Relativamente à subcategoria 1 , o trabalho de equipa é substancial no alcance dos objetivos (MENDES, 2012). O trabalho entre pares e em pequeno grupo faz parte das orientações curriculares para a educação pré-escolar que afirmam a sua relevância como ação "facilitadora do desenvolvimento e aprendizagem". Este método de trabalho permite que as crianças confrontem as suas opiniões, encontrem soluções conjuntas para a mesma atividade. Assim, é natural que a maioria dos comportamentos seja positivo, não se verificando uma distinção entre meninos e meninas, mas uma tendência para o aumento de $\mathrm{CP}$ e diminuição dos CI com o aumento da idade, o que também nos parece natural na medida em que com a evolução dos anos de escolaridade a utilização dos trabalhos em grupo ganha relevância não só na sala de aula, mas também nos recreios e no tipo de jogos e brincadeiras. Segundo Piaget (2010), aos 6/7 anos de idade surgem os jogos de regras com intuito de promover a socialização, onde as regras surgem na tentativa de definir modelos de interação entre pares, papeis a desempenhar e o contexto espácio-temporal. Desta forma, a partir destas idades as crianças entendem a utilização da regra bem como o respeito pela mesma, cooperando com os colegas, envolvendo-se em equipas onde se unem em torno de um único objetivo. $\mathrm{O}$ trabalho em equipa surge e vai-se fortalecendo à medida que as capacidades cognitivas, sociais e emocionais se desenvolvem em cada um. Com este argumento, justificam-se também os resultados relativos à idade na subcategoria 3 que destacam os alunos mais velhos relativamente aos mais novos. 
No que refere à subcategoria 2 foram as meninas quem se destacou nos CP, o que na nossa opinião pode estar relacionado com as brincadeiras preferidas por meninas e meninos. Se por um lado, os meninos são mais competitivos e preferem jogos mais dinâmicos, as meninas preferem atividades de menor dinamismo (CARVALHAL \& VASCONCELOS-RAPOSO, 2007) e com menor recurso à manipulação de objetos, como ficar a conversar, jogar ao "mata" ou "apanhada" (PEREIRA; MOURÃO, 2005), atividades estas que não requerem formação de uma equipa. Por outro lado, Harten, Olds e Dollman (2008) consideram que o jogo praticado pelas meninas é mais cooperativo e como tal, estas têm maior capacidade de incluir do que os meninos. Assim, as meninas através dos jogos cooperativos conseguem relacionar-se com um maior leque de colegas, promovendo mais eficazmente, a sua capacidade de relacionamento do que os meninos que pelo cariz mais competitivo e agressivo dos jogos praticados não permitem que qualquer um os integre, acabando por se concentrarem em grupos mais específicos que não são acessíveis a todos. Também esta razão justifica os resultados da subcategoria 3. A prática de jogos mais competitivos como são os jogos coletivos, onde existe normalmente uma equipa, permite que os meninos melhorem a sua capacidade de negociação e cooperação entre os pares e por isso tenham também a competência associada a esta subcategoria mais desenvolvida do que as meninas.

Verificou-se também na subcategoria 2, quanto à idade, um ligeiro destaque dos alunos mais novos na observação de CP, que podem ser explicados por Pereira e Mourão (2005) que constataram que as crianças mais pequenas, independentemente do género, brincam mais em grande grupo e, com o aumento da idade, a criação de grupos acontece progressivamente.

Assim constatamos que, em cada quatro crianças, três apresentam comportamentos de interação social com uma ou outra das seguintes características, ser capaz de trabalhar em equipa, ser sociável e relacionar-te com os outros ou ter em atenção, considera as ideias e objetivos dos elementos do grupo. No entanto, ainda assim verificamos que uma em cada quatro crianças não revela estas caraterísticas pró-sociais o que nestas idades traduz dificuldade de relacionamento que, caso não haja uma atenção cuidada por parte da escola e da família, pode conduzir ao isolamento das crianças e consequentemente a uma lacuna na promoção de competências de socialização essenciais ao seu desenvolvimento integral. Ainda em relação a estes comportamentos inversos (CI) seria interessante, verificar a sua associação com comportamentos de bullying. É do nosso entendimento que a manifestação deste comportamento é importante mesmo que seja de um modo inverso pois temos 
uma base importante de interação. A dificuldade centra-se no sermos capazes de fazer com que a criança se coloque no lugar do outro, crie empatia e manifeste compreensão pelos pares e pelas suas ideias e opiniões.

Quanto aos comportamentos não observados (CNO), parece-nos que estas crianças revelam dificuldade em interessarem-se pelos outros e pelas práticas o que representa um grupo que merece grande atenção.

\section{Conclusões}

Assim, no final do estudo, concluímos que, é possível afirmar que a participação em jogos estruturados, permite às crianças relacionarem-se, cooperando e apoiando-se mutuamente, sendo a escola um local privilegiado para que tal ocorra. A escola detém um papel fundamental na promoção de competências de relacionamento interpessoal.

Retirar da criança a oportunidade de jogar é negligenciar o seu desenvolvimento, é limitar as suas capacidades e dificultar a sua integração no mundo, na verdade, é não permitir que seja criança.

Assim sugerimos que sejam realizados programas de intervenção ao nível da comunidade educativa incluindo professores, funcionários, alunos e encarregados de educação para realçar a relevância do jogar e brincar, essencial ao desenvolvimento destas competências que para além dos benefícios a curto prazo poderão ser também relevantes no futuro. Contudo estes programas devem ter em consideração a existência de CI, e encontrar estratégias para transformar estes comportamentos em atitudes positivas promovendo o trabalho em equipa, momentos de discussão e debate permitindo que todos participem, opinem e respeitem a opinião dos outros.

Este estudo sobre as caraterísticas empreendedoras das crianças é um estudo inovador que vem preencher uma lacuna na investigação científica e, por isso, também se recomenda a realização de outras investigações com crianças aplicando os mesmos instrumentos que se revelaram motivadores para as crianças permitindo a recolha de informação junto das crianças com qualidade e rigor.

\section{Nota}

1 Este trabalho foi financiado por Fundos Nacionais através da FCT - Fundação para a Ciência e a Tecnologia no âmbito do projeto do CIEC (Centro de Investigação em Estudos da Criança da Universidade do Minho) com a referência UID/CED/00317/2019. 


\section{Referências}

BROUGÈRE, Gilles. A criança e a cultura lúdica. Revista da Faculdade de Educação, v. 24, n. 2, p. 103-116, 1998.

CARVALHAL, Maria Isabel; VASCONCELOS-RAPOSO, José. Diferenças entre géneros nas habilidades: correr, saltar, lançar e pontapear. Motricidade, v. 3, n.3, p. 44-56. 2007.

FILGUEIRAS, Izabel. A criança e o movimento. Questões para pensar a prática pedagógica na Educação Infantil e no Ensino Fundamental. Revista Avisa lá, v. 11. 2002.

GINSBURG, Kenneth. The Importance of Play in Promoting Healthy Child Development and Maintaining Strong Parent-Child Bonds. Pediatrics, v. 119, n. 1, p. 181-192. 2007.

HARTEN, Nathan., OLDS, Tim; DOLLMAN, Jim. The effects of gender, motor skills and play area on the free play activities of 8-11 year old school children. Health \& Place, v. 14, n. 3, p. 386-393. 2008.

HUBER, Laura., SLOOF, Randolph; PRAAG, Mirjam. The Effect of Early Entrepreneurship Education: Evidence from a Randomized Field Experiment. IZA Discussion Paper Series, v. 30, 2012 .

HUIZINGA, Johan. Homo Ludens. Lisboa: Edições 70, 2003.

HURWITZ, Sally. To be successful, let them play! (For Parents Particularly). Childhood Education, v. 79, n. 2, p. 101-102. 2003.

KISHIMOTO, Tizuko. O jogo e a educação infantil. São Paulo: Pioneira, 1998.

MENDES, Fernando. Start iUPi - Fazer Coisas. Oeiras: Blue Go, LDA, 2012

MIHAELA, Păişi. Play in school context. Procedia - Social and Behavioral Sciences, v. 76, p. 597-601. 2013.

MILTEER, Regina; GINSBURG, Kenneth. The Importance of Play in Promoting Healthy Child Development and Maintaining Strong Parent-Child Bond: Focus on Children in Poverty. Pediatrics, v. 129, n. 1, p. 203-213. 2012.

NETO, Carlos. Jogo na criança \& Desenvolvimento Psicomotor. Lisboa: Faculdade de Motricidade Humana, Universidade Técnica de Lisboa, 1997.

PELLEGRINI, Anthony; BOHN, Catherine. The Role of Recess in Children's Cognitive Performance and School Adjustment. Educational Research, v. 34, n. 1, p. 13-19. 2005.

PEREIRA, Sissi; MOURÃO, Ludmila. Identificações de gênero: jogando e brincando em universos divididos. Motriz, v. 11, n. 3, p. 205-210. 2005.

PIAGET, Jean. A Formação do Símbolo na Criança: Imitação Jogo e Sonho Imagem e Representação (4 ed.). LTC, 2010.

WALLON, Henri. A Evolução Psicológica da Criança. Edições 70, 1998. 